\title{
Peripheral blood mononuclear cells from field cattle immune to bovine viral diarrhea virus (BVDV) are permissive in vitro to BVDV
}

\author{
V. GUPTA, N. MISHRA*, A. PATERIYA, S. P. BEHERA, K. RAJUKUMAR
}

High Security Animal Disease Laboratory, Indian Veterinary Research Institute, Anand Nagar, Bhopal, Madhya Pradesh, 462021, India

Received July 30, 2013; accepted April 9, 2014

\begin{abstract}
Summary. - The aim of this study was to determine the in vitro permissivity of peripheral blood mononuclear cells (PBMCs) from bovine viral diarrhea virus (BVDV)-immune field cattle to homologous and heterologous BVDVs. PBMCs from seventeen BVDV-naïve and sixteen BVDV-immune animals were infected with noncytopathic BVDV-1 or BVDV-2. The immune status of cattle was indicated by the presence of virus neutralizing antibodies, while viral load of PBMCs was determined by real-time RT-PCR. The results revealed that the PBMCs from naïve or immune animals were permissive to either BVDV-1 or BVDV-2, but the viral load was significantly higher for the naïve than for the immune animals. Furthermore, the load of homologous virus in PBMCs from immune animals was lower than that of heterologous virus. Our results provide evidence that the PBMCs from BVDV-immune cattle in field are susceptible to reinfection with homologous or heterologous BVDV, albeit to a lower extent in the former case.
\end{abstract}

Keywords: bovine viral diarrhea virus; peripheral blood mononuclear cells; cattle; immunity; virus permissivity in vitro

\section{Introduction}

Bovine viral diarrhea (BVD), an economically important viral disease of cattle is prevalent worldwide. The causative agents of BVD, bovine viral diarrhea virus 1 (BVDV-1) and bovine viral diarrhea virus 2 (BVDV-2) together with border disease virus (BDV) and classical swine fever virus belong to the genus Pestivirus in the family Flaviviridae (King et al., 2011). Additionally, atypical bovine pestivirus, a candidate for BVDV-3 species (Liu et al., 2009) has been identified recently. BVDV-1 strains are prevalent in cattle populations around the world, while BVDV-2 strains occur sporadically except for few exceptions. The BVDV genome is approximately $12.3 \mathrm{~kb}$ long

*Corresponding author. E-mail: mishranir@rediffmail.com; phone: +91-755-2758842.

Abbreviations: $\mathrm{BVD}=$ bovine viral diarrhea; $\mathrm{BVDV}-1=\mathrm{BVD}$ virus $1 ; \mathrm{BVDV}-2=\mathrm{BVD}$ virus $2 ; \mathrm{ncp}=$ noncytopathic; $\mathrm{PBMCs}=$ peripheral blood mononuclear cells; p.i. $=$ post infection single-stranded positive-sense RNA containing one large ORF that encodes a single poly-protein of about 3,900 aa flanked by UTR at both ends which is cleaved into four structural and 7-8 nonstructural proteins by viral and host cell proteases (Meyers and Thiel, 1996). Based on genetic characterization, BVDV-1 species has been divided into at least 16 subtypes and BVDV-2 species into 2 subtypes (Vilcek et al., 2001; Jackova et al., 2008).

On the basis of their effect on cultured cells, BVDV strains have been classified into two biotypes, cytopathic and noncytopathic (ncp). Ncp BVDVs are the prominent biotypes in the field and cause persistent infection, vital for transmission and survival of BVDV. BVDV infection in susceptible cattle can lead to either acute infection in immuno-competent animals, persistent infection in developing, immunologically naïve bovine fetus or a chronic infection within immune-privileged sites (testicular tissue, ovarian tissue and central nervous system's tissue) following transient infection (Voges et al., 1998; Grooms et al., 1998; Givens et al., 2003; Blas-Machado et al., 2004). Cattle with 
prolonged BVDV infection will develop a significant immune response accompanied by high neutralizing antibody titers (Voges et al., 1998; Givens et al., 2003).

Both ncp/cytopathic BVDVs infect peripheral blood mononuclear cells (PBMCs), which are pivotal in control of the innate and acquired immune response in cattle. These cells include granulocytes, monocytes, null cells, macrophages, antigen-presenting cells, myeloid cells, CD4+ and CD8+ T-lymphocytes and B cells (Chase et al., 2004). Of these, the $\mathrm{B}$ cells population seems to make only minor contribution (Ohmann et al.,1987), while infection of antigen presenting cells with BVDV perturbs the normal pathway of immune stimulation thereby leading to immune evasion and chronic infection (Glew et al., 2003).

Generally, following an acute infection, BVDV can be isolated or detected in PBMCs up to 14 days post infection (p.i.) when neutralizing antibodies become detectable. However, BVDV has been detected in circulating PBMCs from seropositive cattle (Gogorza et al., 2005). Recently, it has also been demonstrated that prolonged BVDV infection can occur in PBMCs in acutely infected calves even in presence of neutralizing antibodies (Collins et al., 2009). But the detail mechanism of persistence of BVDV in BVDV-immune animals has not yet been elucidated and it is not known, whether PBMCs from BVDV-immune cattle in field following natural infection can be re-infected with BVDVs. Hence, the aim of this study was to determine the in vitro permissivity of PBMCs from BVDV-immune field cattle to homologous and heterologous BVDVs.

\section{Materials and Methods}

Viruses and cells. Indian cattle BVDV-1b strain, Ind S-1449 (Mishra et al., 2004) and BVDV-2a strain, Ind 141353 (Behera et al., 2011) were used in this study. MDBK cells obtained from Collection of cell lines in veterinary medicine, Riems, Germany (kind gift by Roland Riebe) were used for virus propagation and virus neutralization tests. The cells were grown in Eagle's MEM (Sigma Aldrich) containing 10\% horse serum (Life Tech, USA) and maintained at $37^{\circ} \mathrm{C}$ with $5 \% \mathrm{CO}_{2}$ atmosphere. The cells were tested for presence of any adventitious pestivirus contamination by RT-PCR using panpestivirus specific primers.

Infectious virus titration. Following propagation in MDBK cells, the titre of the stock viruses was determined by immunoperoxidase monolayer assay (IPMA) using BVDV polyclonal antibodies (VMRD, USA) as described earlier (Mishra et al., 2008).

Animals selection and blood handling. Whole blood samples collected from cattle of different geographic areas during October 2012 and April 2013 were used in the study. Blood leukocytes were tested for BVDV by virus isolation or RT-PCR using standard methods.
Virus neutralization test. The sera separated from blood were tested for the presence of BVDV antibodies by using BVDV-1 and BVDV-2, MDBK cells and immunoperoxidase monolayer assay as described earlier (Mishra et al., 2008). Seventeen BVDV-naïve animals were selected from a BVV-free and BVDV-antibody-free dairy herd while sixteen BVDV-immune animals were selected from four different dairy herds. Serum samples from sixteen BVDV-immune cows were further subjected to end point virus neutralizing antibody titration for ascertaining BVDV-1 or BVDV-2 infection present in the field.

Isolation and cultivation of PBMCs. PBMCs were separated from $2 \mathrm{ml}$ of blood from BVDV-immune $(\mathrm{n}=16)$ and BVDV-naïve animals $(\mathrm{n}=17)$ by density gradient centrifugation with Histopaque 1078 (Sigma-Aldrich) following the earlier reported protocol (Collins et al. 2009) with some modifications. Cells were counted and checked for viability by dye exclusion method using $0.4 \%$ trypan blue. Appropriate volume of RPMI-1640 (Sigma-Aldrich) supplemented with 10\% FCS (Sigma-Aldrich), 200 mmol/l glutamine, $100 \mathrm{IU} / \mathrm{ml}$ penicillin and $100 \mu \mathrm{g} / \mathrm{ml}$ of streptomycin was added to obtain a concentration of $2 \times 10^{6}$ cells $/ \mathrm{ml}$ of PBMC culture medium. PBMCs suspended in $0.25 \mathrm{ml}$ of PBMC culture medium containing $5 \times 10^{5}$ cells were seeded in each well of 24 -well TC plate and were incubated at $37^{\circ} \mathrm{C}$ in $5 \% \mathrm{CO}_{2}$ atmosphere.

Infection of PBMCs cultures with BVDVs. After $24 \mathrm{hr}$ of culture, old PBMC culture medium was removed and PBMCs were infected with BVDV-1 or BVDV-2 at MOI = 1 in duplicate wells. Uninfected PBMCs in a well served as negative control. Infected PBMCs were incubated for $90 \mathrm{~min}$ at $37^{\circ} \mathrm{C}$ for virus adsorption before washing with plain RPMI-1640 medium and adding fresh PBMC culture medium. The infected PBMCs were incubated for $24 \mathrm{hr}$ at $37^{\circ} \mathrm{C}$ in $5 \% \mathrm{CO}_{2}$ atmosphere and then kept frozen at $-80^{\circ} \mathrm{C}$ until tested for viral load by real time RT-PCR.

Real-time RT-PCR assay of viral load. Total RNA was extracted from frozen and thawed cell culture containing PBMCs including culture medium ( $0.25 \mathrm{ml}$ ) using TRI Reagent (Ambion, USA) following the manufacturer's recommendations. Pelleted RNA was resuspended in $30 \mu \mathrm{l}$ of nuclease free water and was stored at $-80^{\circ} \mathrm{C}$ until use. Extracted RNA from infected and uninfected PBMCs was subjected to quantification of viral load by one-step TaqMan real time RT-PCR using Light Cycler 480 (Roche), SuperScript III Platinum One-Step Quantitative RT-PCR system (Invitrogen, USA), primers 190F (Hoffmann et al., 2006), V326 (Vilcek et al., 1994) and probe TQPESTI (Gaede et al., 2005) according to the protocol described earlier (Hoffmann et al., 2006). The viral load in PBMCs from each BVDV-naïve and BVDV-immune cattle was calculated in relationship to the reference virus calibrator (BVDV-1 or BVDV-2) and expressed as $\mathrm{TCID}_{50}$ /assay. For preparation of standard curve, 10-fold dilutions of RNA from the reference virus corresponding to a virus titer of $10^{5} \mathrm{TCID}_{50} / \mathrm{ml}$ were made and tested by real time RT-PCR in triplicate. Adequate precautions were taken to avoid cross contamination by including positive control, negative control (uninfected PBMCs), no template control and extraction control. Data on virus loads were analyzed by standard statistical procedures and Kruskal-Wallis test. 
Table 1. BVDV load in PBMCs from BVDV-naïve cattle

\begin{tabular}{|c|c|c|c|c|}
\hline Animal No. & No. of PBMCs $/ \mathrm{ml}$ & Cell (\%) viability & $\begin{array}{l}\text { BVDV-1 load } \\
\text { (TCID }_{50} \text { /assay) }\end{array}$ & $\begin{array}{l}\text { BVDV-2 load } \\
\text { (TCID }_{50} \text { /assay) }\end{array}$ \\
\hline 296806 & $1.3 \times 10^{6}$ & 91 & 0.680 & 0.387 \\
\hline 296774 & $3.2 \times 10^{6}$ & 98 & 0.378 & 0.3195 \\
\hline 296805 & $1.7 \times 10^{6}$ & 95 & 0.359 & 0.251 \\
\hline 296775 & $2.6 \times 10^{6}$ & 92 & 0.746 & 0.260 \\
\hline 296777 & $1.4 \times 10^{6}$ & 97 & 0.693 & 0.2466 \\
\hline 296813 & $1.3 \times 10^{6}$ & 93 & 0.531 & 0.3168 \\
\hline 296810 & $1 \times 10^{7}$ & 94 & 0.288 & 0.2367 \\
\hline 296788 & $1.7 \times 10^{6}$ & 90 & 0.282 & 0.497 \\
\hline 295971 & $8.4 \times 10^{6}$ & 98 & 0.171 & 0.1426 \\
\hline 295975 & $1.1 \times 10^{7}$ & 98 & 0.1746 & 0.1426 \\
\hline 295967 & $1.1 \times 10^{7}$ & 98 & 0.6682 & 0.188 \\
\hline 296905 & $2.5 \times 10^{4}$ & 98 & 0.655 & 0.5539 \\
\hline 296900 & $9 \times 10^{5}$ & 97 & 0.8226 & 0.5165 \\
\hline 296912 & $7.5 \times 10^{5}$ & 92 & 0.6493 & 0.4023 \\
\hline 296921 & $4 \times 10^{5}$ & 95 & 0.4927 & 0.6453 \\
\hline 296864 & $1.2 \times 10^{6}$ & 93 & 0.4837 & 0.5165 \\
\hline 296860 & $6 \times 10^{5}$ & 96 & 0.4023 & 0.4023 \\
\hline \multicolumn{2}{|c|}{ Mean viral load $(n=17)$} & & $0.498 \pm 0.203$ & $0.354 \pm 0.151$ \\
\hline
\end{tabular}

Table 2. BVDV load in PBMCs from BVDV-1-immune cattle

\begin{tabular}{|c|c|c|c|c|c|c|}
\hline Animal No. & No. of PBMCs/ml & Cell (\%) viability & $\begin{array}{c}\text { BVDV-1 } \\
\text { antibody titer }\end{array}$ & $\begin{array}{c}\text { BVDV-2 } \\
\text { antibody titer }\end{array}$ & $\begin{array}{l}\text { BVDV-1 load } \\
\text { (TCID }_{50} \text { /assay) }\end{array}$ & $\begin{array}{l}\text { BVDV-2 load } \\
\text { (TCID }_{50} \text { /assay) }\end{array}$ \\
\hline 130213 & $1.5 \times 10^{5}$ & 94 & $1: 80$ & $1: 40$ & 0.210 & 0.252 \\
\hline 296614 & $1.66 \times 10^{6}$ & 98 & $1: 80$ & $1: 40$ & 0.162 & 0.344 \\
\hline 296616 & $3.2 \times 10^{6}$ & 92 & $1: 160$ & $1: 40$ & 0.124 & 0.306 \\
\hline 296627 & $3.6 \times 10^{6}$ & 95 & $1: 40$ & $1: 10$ & 0.247 & 0.411 \\
\hline 296638 & $1.4 \times 10^{6}$ & 97 & $1: 80$ & $1: 20$ & 0.198 & 0.273 \\
\hline 296641 & $3 \times 10^{5}$ & 91 & $1: 160$ & $1: 20$ & 0.214 & 0.291 \\
\hline 296613 & $2 \times 10^{6}$ & 93 & $1: 40$ & $1: 10$ & 0.234 & 0.375 \\
\hline 296619 & $2.5 \times 10^{5}$ & 94 & $1: 160$ & $1: 10$ & 0.236 & 0.380 \\
\hline 296623 & $1.5 \times 10^{5}$ & 95 & $1: 160$ & $1: 40$ & 0.222 & 0.360 \\
\hline 296631 & $5 \times 10^{5}$ & 95 & $1: 40$ & $1: 20$ & 0.2358 & 0.2664 \\
\hline \multicolumn{2}{|c|}{ Mean viral load $(n=10)$} & & & & $0.208 \pm 0.04$ & $0.325 \pm 0.06$ \\
\hline
\end{tabular}

Table 3. BVDV load in PBMCs from BVDV-2-immune cattle

\begin{tabular}{|c|c|c|c|c|c|c|}
\hline Animal No. & No. of PBMCs/ml & Cell (\%) viability & $\begin{array}{c}\text { BVDV-1 } \\
\text { antibody titer }\end{array}$ & $\begin{array}{c}\text { BVDV-2 } \\
\text { antibody titer }\end{array}$ & $\begin{array}{l}\text { BVDV-1 load } \\
\text { (TCID }_{50} \text { /assay) }\end{array}$ & $\begin{array}{l}\text { BVDV-2 load } \\
\text { (TCID }_{50} \text { /assay) }\end{array}$ \\
\hline 130213 & $2.5 \times 10^{5}$ & 92 & $1: 80$ & $1: 160$ & 0.269 & 0.150 \\
\hline 130213 & $3.5 \times 10^{5}$ & 94 & $1: 80$ & $1: 160$ & 0.339 & 0.136 \\
\hline 296608 & $3 \times 10^{6}$ & 98 & $1: 160$ & $1: 320$ & 0.264 & 0.173 \\
\hline 296612 & $5 \times 10^{6}$ & 91 & $1: 40$ & 1.80 & 0.368 & 0.146 \\
\hline 296863 & $5.5 \times 10^{5}$ & 97 & $\mathrm{~N}$ & $1: 10$ & 0.410 & 0.213 \\
\hline 296864 & $4 \times 10^{5}$ & 95 & $1: 20$ & $1: 40$ & 0.421 & 0.237 \\
\hline \multicolumn{2}{|c|}{ Mean viral load $(\mathrm{n}=6)$} & & & & $0.345 \pm 0.06$ & $0.175 \pm 0.04$ \\
\hline
\end{tabular}




\section{Results}

The results of viral load by real-time RT-PCR showed that in PBMCs from BVDV-naïve cattle, the mean $( \pm S D$ ) viral load of BVDV- 1 was $0.498 \pm 0.203$ TCID $_{50}$ /assay, while the BVDV-2 viral load was $0.354 \pm 0.151 \mathrm{TCID}_{50}$ /assay (Table 1 ).

BVDV-naïve animals were seronegative to both BVDV-1 and BVDV-2 and on the basis of neutralizing antibody titers, from 16 BVDV-immune cows ten were classified as BVDV-1 -immune and six cows as BVDV-2-immune (Table 2 and 3). Since vaccination against BVDV has never been used in India, BVDV-immune cattle were supposed to be infected naturally with BVDV in the field.

In PBMCs from BVDV-1-immune cattle $(\mathrm{n}=10)$, the mean BVDV-1 viral load was $0.208 \pm 0.04 \mathrm{TCID}_{50}$ /assay and the mean BVDV-2 viral load was $0.325 \pm 0.06 \mathrm{TCID}_{50} /$ assay (Table 2). Similarly, in PBMCs from BVDV-2-immune cattle, the mean BVDV-1 viral load was $0.345 \pm 0.067 \mathrm{TCID}_{50} /$ assay and the mean BVDV-2 viral load was $0.175 \pm 0.040$ TCID $_{50} /$ assay (Table 3). Taken together, the results revealed that $\mathrm{PB}-$ MCs of both BVDV-naïve and BVDV-immune cattle could be infected by both BVDV-1 and BVDV-2 although the viral load was significantly higher in PBMCs from BVDV-naïve cattle $(\mathrm{P}>0.05)$ than in PBMCs from BVDV-immune cattle in the field (Table 2 and 3, Fig. 1).

\section{Discussion}

BVDV-1 and BVDV-2 ncp viruses were used for infecting PBMCs from BVDV-naïve and BVDV-immune field cattle in this study, since ncp biotype of BVDV is the major infecting biotype, BVDV-1 and BVDV-2 are prevalent in cattle in most parts of the world including India (Mishra et al., 2004; Ridpath et al., 2010; Behera et al., 2011). In a previous study, the viral load of BVDV-1 in PBMCs from BVDV-naïve cattle has been reported as $1.24 \pm 2.12 \mathrm{TCID}_{50} /$ assay and that of BVDV-2 as 2 TCID $_{50}$ /assay (Lucchini et al., 2012). Another study showed that the viral load of BVDV-1 in PBMCs from BVDV-naïve cattle was $2.84 \pm 2.83$ TCID $_{50} /$ assay $18 \mathrm{hr}$ p.i. and $35.03 \pm 31.90 \mathrm{TCID}_{50} /$ assay $36 \mathrm{hr}$ p.i. (Turin et al., 2013). A lower viral load for both BVDV-1 and BVDV-2 was evident in our study compared to the results of Lucchini et al. (2012), while the BVDV-1 load was almost similar to that found by Turin et al., 2013. Since the assays for viral load in PBMCs were performed $24 \mathrm{hr}$ p.i., it is likely that the replication cycle was complete at the time of assay, as BVDV eclipse period has been reported to be completed at about $12 \mathrm{hr}$ in bovine cells (Gong et al., 1996) and although one-step growth curve has yet to be determined in PBMCs, highest viral load of BVDV-1 in PBMCs from BVDV-naïve cattle has been found $36 \mathrm{hr}$ p.i. (Turin et al., 2013). Hence, viral load in PBMCs may be

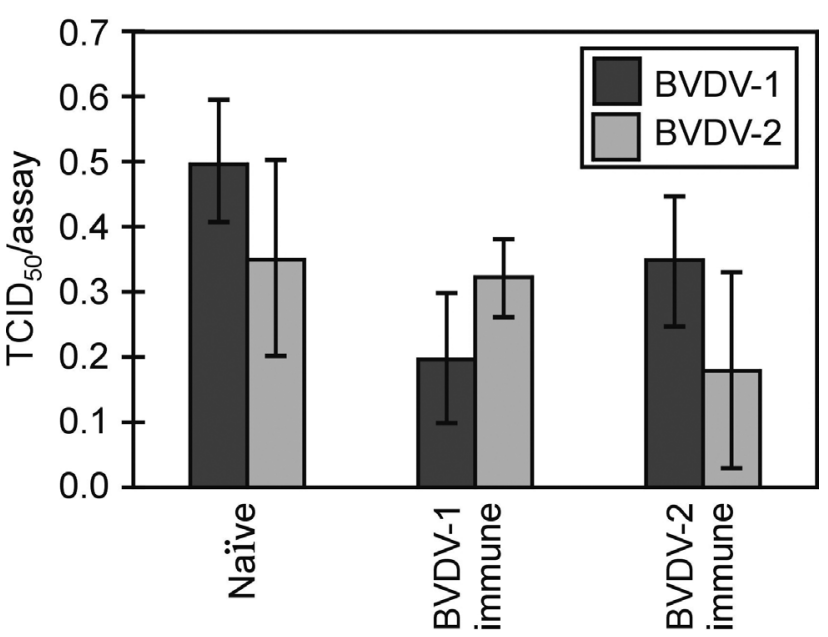

Fig. 1

Viral loads in PBMCs from BVDV-naïve and BVDV-immune cattle Mean values ( \pm standard error) of viral load in PBMCs are shown.

strain dependent due to difference in efficiency in adsorption and/or replication of BVDVs.

Difference in efficiency of replication of BVDV-1 or BVDV-2 in PBMCs has been reported earlier (Lucchini et al., 2012; Turin et al., 2013). However, in contrast to a previous study (Lucchini et al., 2012), our results showed that the viral load of BVDV-1 was higher than BVDV-2 in PBMCs from BVDV-naïve cattle which may be due to the difference in BVDV strains used. Low viral load of ncp BVDVs in cattle is however not unusual, since it provides an efficient mechanism for virus survival in nature.

A previous study has shown that lymphocytes from BVDV-naïve cattle were more efficiently infected in vitro than those of BVDV vaccinated cattle (Beer et al., 1997). Recently, a study involving infection of PBMCs obtained from BVDV-naïve and BVDV-1b experimentally immune cattle with viruses belonging to BVDV-1a, BVDV-1b and BVDV-2a subtypes showed that BVDV-naive cattle had higher viral load than that of BVDV experimentally immune cattle (Lucchini et al., 2012). Here we also demonstrated that BVDV-naïve cattle had higher viral load than BVDVimmune field cattle.

BVDV has earlier been detected in PBMCs from BVDVimmune animals (Gogorza et al., 2005) and a long term persistent infection has been demonstrated in PBMCs following acute infection where BVDV could be transferred to naïve calves via blood transfusion (Collins et al., 2009). Hence, humoral response against BVDV alone may not be adequate for efficient clearance of BVDV from PBMCs of BVDV infected animals. It has been shown previously that infection of antigen presenting cells in PBMCs with BVDV 
can adversely affect their ability to interact with and stimulate T-cell responses which may be a critical viral strategy for immune evasion (Glew et al., 2003). Our results revealed that in PBMCs from BVDV-1 and BVDV-2-immune cattle, the viral load of heterologous virus was more than the homologous virus indicating that cell-mediated immune response is involved in determination of viral load. Although the time of exposure of field cattle with BVDV was not determined, this study for the first time demonstrated that PBMCs from BVDV-immune field cattle are susceptible to re-infection with BVDV.

In conclusion, our results showed that PBMCs from BVDV-immune cattle naturally infected in the field are susceptible to re-infection with both homologous and heterologous BVDVs, although to a lower extent with the former case. Re-infection of PBMCs of BVDV-immune cattle can have epidemiological significance for control of BVD.

Acknowledgements. V. Gupta was supported by a post graduate fellowship from Indian Veterinary Research Institute, Izatnagar, Bareilly, Uttar Pradesh, India and N. Mishra was supported by a grant (78/2009) from the Indian Veterinary Research Institute.

\section{References}

Beer M, Wolf G, Pichler J, Wolfmeyer A, Kaaden OR (1997): Cytotoxic T-lymphocyte responses in cattle infected with bovine viral diarrhoea virus. Vet. Microbiol. 58, 9-22. http://dx.doi.org/10.1016/S0378-1135(97)00145-4

Behera SP, Mishra N, Vilcek S, Rajukumar K, Nema RK, Prakash A, Kalaiyarasu S, Dubey SC (2011): Genetic and antigenic characterization of bovine viral diarrhoea virus type 2 isolated from cattle in India. Comp. Immunol. Microbiol. Infect. Dis. 34, 189-196. http://dx.doi.org/10.1016/j. cimid.2010.11.002

Blas-Machado U, Saliki JT, Duffy JC, Caseltine SL (2004): Bovine viral diarrhoea virus type 2 -induced meningoencephalitis in a heifer. Vet. Pathol. 41, 190-194. http://dx.doi. org/10.1354/vp.41-2-190

Chase CC, Elmowalid G, Yousif AA (2004): The immune response to bovine viral diarrhoea virus: A constantly changing picture. Vet. Clinics of North America: Food Anim. Pract. 20, 95-114. http://dx.doi.org/10.1016/j.cvfa.2003.11.004

Collins ME, Heaney J, Thomas CJ, Brownlie J (2009): Infectivity of pestivirus following persistence of acute infection. Vet. Microbiol. 138, 289-296. http://dx.doi.org/10.1016/j. vetmic.2009.04.022

Gaede W, Reiting R, Schirrmeier H, Depner KR, Beer M (2005): Detection and species-specific differentiation of pestiviruses using real-time RT-PCR. Berl. Munch. Tierarztl. Wochenscher. 118, 113-120.

Givens MD, Heath AM, Brock KV, Brodersen BW, Carson RL, Stringfellow DA (2003): Detection of bovine viral diarrhoea virus in semen after infection of seronegative, post-pubertal bulls. Am. J. Vet. Res. 64, 428-434. http:// dx.doi.org/10.2460/ajvr.2003.64.428

Glew EJ, Carr BV, Brackenbury LS, Hope JC, Charleston B, Howard CJ (2003): Differential effects of bovine viral diarrhoea virus on monocytes and dendritic cells. J. Gen. Virol. 84, 1771-1780. http://dx.doi.org/10.1099/vir.0.18964-0

Gogorza LM, Moran PE, Larghi JL, Segui R, Lissarrague C, Saracco M (2005): Detection of bovine viral diarrhoea virus (BVDV) in seropositive cattle. Prev. Vet. Med. 72, 49-54. http://dx.doi.org/10.1016/j. prevetmed.2005.07.015

Gong Y, Rachel T, Thomas M, Edwin W, Anthony S, Eric G (1996): Characteristic of RNA synthesis during a one step growth curve and replication mechanism of bovine viral dairrhoea virus. J. Gen. Virol. 77, 2729-2736. http://dx.doi. org/10.1099/0022-1317-77-11-2729

Grooms DL, Brock KV, Ward LA (1998): Detection of bovine viral diarrhoea virus in the ovaries of cattle acutely infected with bovine viral diarrhoea virus. J. Vet. Diagn. Invest. 10, 125-129. http://dx.doi. org/10.1177/104063879801000201

Hoffmann B, Depner K, Schirrmeier H, Beer M (2006): A universal heterologous internal control system for duplex real-time RT-PCR assays used in a detection system for pestiviruses. J. Virol. Meth. 136, 200-209. http://dx.doi.org/10.1016/j. jiromet.2006.05.020

Jackova A, Novackova M, Pelletier C, Audeval C, Gueneau E, Haffer A, Petit E, Rehby L, Vilcek S (2008): The extended genetic diversity of BVDV-1: typing of BVDV isolates from France. Vet. Res. Comm. 32, 7-11. http://dx.doi. org/10.1007/s11259-007-9012-Z

King AMQ, Adams MJ, Carstens EB, Lefkowitz EJ (Eds) (2011): Virus Taxonomy: Classification and Nomenclature of Viruses: Ninth Report of the International Committee on Taxonomy of Viruses. Academic Press, San Diego, pp. 1003-1020.

Liu L, Kampa J, Belak S, Baule C (2009): Virus recovery and full length sequence analysis of atypical bovine pestivirus Th/04 khonken. Vet. Microbiol. 138, 62-68. http://dx.doi. org/10.1016/j.vetmic.2009.03.006

Lucchini B, Ponti W, Turin L, Bronzo V, Scaccabarozzi L, Luzzago C (2012). In vitro permissivity of bovine peripheral blood mononuclear cells to bovine viral diarrhoea virus is dependent on the animal specific immune status. Vet. J. 192, 126-128. http://dx.doi.org/10.1016/j.tvjl.2011.05.001

Meyers G, Thiel HJ (1996): Molecular characterization of pestivirus. Adv. Virus Res. 47, 53-68. http://dx.doi.org/10.1016/ S0065-3527(08)60734-4

Mishra N, Pattnaik B, Vilcek S, Patil SS, Jain P, Swamy N, Bhatia S, Pradhan HK (2004): Genetic typing of bovine viral diarrhoea virus isolates from India. Vet. Microbiol. 104, 207212. http://dx.doi.org/10.1016/j.vetmic.2004.08.003

Mishra N, Rajukumar K, Vilcek S, Tiwari A, Satav JS, Dubey, SC (2008): Molecular characterization of bovine viral diarrhoea virus type 2 isolate originating from a native Indian sheep (Ovis aries) Vet. Microbiol. 130, 88-98. http:// dx.doi.org/10.1016/j.vetmic.2008.01.005 
Ohmann BH, Rønsholt L, Bloch B (1987): Demonstration of bovine viral diarrhoea virus in peripheral blood mononuclear cells of persistently infected, clinically normal cattle. J. Gen. Virol. 68, 1971-1982. http://dx.doi.org/10.1099/0022$\underline{1317-68-7-1971}$

Ridpath JF, Fulton RW, Kirkland PD, Neill JD (2010): Prevalence and antigenic differences observed between bovine viral diarrhea virus subgenotypes isolated from cattle in Australia and feedlots in the southwestern United States. J. Vet. Diagn. Invest. 22, 184-191. http://dx.doi. org $/ 10.1177 / 104063871002200203$

Turin L, Lucchini B, Bronzo V, Luzzago C (2013): In vitro Replication Activity of Bovine Viral Diarrhea Virus in an Epithelial Cell Line and in Bovine Peripheral Blood Mononuclear Cells. J. Vet. Med. Sci. 74, 1397-1400. http:// dx.doi.org/10.1292/jvms.12-0011
Voges H, Horner GW, Rowe S, Wellenberg GJ (1998): Persistent bovine pestivirus infection localized in the testes of an immuno-competent, non-viraemic bull. Vet. Microbiol. 61, 165-175. http://dx.doi.org/10.1016/S0378$\underline{1135(98) 00177-1}$

Vilcek S, Herring AJ, Herring JA, Nettleton PF, Lowings JP, Paton DJ (1994): Pestiviruses isolated from pigs, cattle and sheep can be allocated into at least three genogroups using polymerase chain reaction and restriction endonuclease analysis. Arch. Virol. 136, 309-323. http://dx.doi.org/10.1007/BF01321060

Vilcek S, Paton DJ, Durkovic B, Strojny L, Ibata G, Moussa A, Loitsch A, Rossmanith W, Vega S, Scicluna MT, Palfi V (2001): Bovine viral diarrhoea virus genotype 1 can be separated into at least eleven genetic groups. Arch. Virol. 146, 99-115. http://dx.doi.org/10.1007/s007050170194 